\title{
The Russian particle zhe in the light of parallel corpora
}

\author{
Alexei Shmelev \\ Vinogradov Russian Language Institute \\ of the Russian Academy of Sciences / \\ Volkhonka 18/2, Moscow, Russia \\ Moscow Pedagogical State University / \\ Moscow, Russia \\ shmelev.alexeiegmail.com
}

\begin{abstract}
This paper deals with the Russian particle $z$ he and its use in the Russian translations from English and demonstrates the possibilities of "one-focus analysis" in contrastive studies based on the parallel corpora. It correlates the explications of zhe given in earlier studies (it makes special reference to the Active Dictionary of Russian) with the stimuli to translation, that is, fragments of the original English text that might cause the appearance of $z h e$ in a Russian translation as a reaction to those stimuli. The study sought to validate, disprove or improve the semantic analysis of zhe made without recourse to electronic corpora.

The analysis of the stimuli that have led Russian translators to use the particle zhe reveals important characteristics of this word. It turns out that the Russian particle $z$ he is often pragmatically obligatory as its absence would violate the idiomatic nature of the utterance and change its illocutionary force. It is often the case that if a translator had given word-for-word translation, that is without a particle, they would convey the precise meaning, but the translation would be inadequate: the wrong implicature would appear. On the other hand, when they add the particle, they may impart new shades of meaning which the original text did not contain.
\end{abstract}

Keywords: semantics, language-specific particles, translation, parallel corpora, lexicography

DOI: $10.28995 / 2075-7182-2021-20-626-635$

\section{Русская частица же в зеркале параллельных корпусов}

\author{
Алексей Шмелев \\ Институт русского языка им. В.В. Виноградова \\ РАН / Волхонка 18/2, Москва, Россия \\ Московский педагогический государственный \\ университет / Москва, Россия \\ shmelev.alexei@gmail.com
}

В статье рассматривается семантика русской частицы же на основе ее функционирования в англо-русском параллельном подкорпусе «Национального корпуса русского языка» (НКРЯ). Делается попытка подтвердить, опровергнуть или уточнить существующие описания, в частности в «Активном словаре русского языка» (Левонтина 2017; далее - АC).

Очевидно, что в английских оригиналах нет и не может быть единицы, для которой же было бы непосредственным переводным соответствием. Установив, каковы были причины, побудившие переводчика использовать эту частицу в русском тексте, мы имеем шанс проникнуть в ее семантические секреты, до сих пор ускользавшие от внимания или описанные неточно.

Итак, в центре внимания находится функционирование лингвоспецифичной частицы же в переводных текстах (в переводах с английского языка). Иными словами, исследование выполнено в русле «монофокусного» анализа ${ }^{1}$. Важно, что, в отличие от контрастивных корпусных

\footnotetext{
This paper has been written with the support of RFBR (project \# 19-012-00505).

${ }^{1}$ В более ранних публикациях мы называли такой анализ «унидирекциональным» (Шмелев, Зализняк 2017: 370).
} 
исследований, при таком анализе в центре внимания оказывается именно язык переводных текстов (в нашем случае русский), тогда как оригинальные тексты (в нашем случае - английские) используются как средство для выявления «семантического задания», стоящего перед переводчиком. Если сопоставительные исследования частиц на базе параллельных корпусов имеют уже относительно давнюю традицию и возможности использования параллельных корпусов для таких исследований демонстрировались в том числе в рамках конференции «Диалог» ${ }^{2}$, то «монофокусные» исследования дискурсивных слов на базе параллельных корпусов стали осуществляться относительно недавно ${ }^{3}$.

Вообще говоря, частица же неоднократно была предметом внимания со стороны лингвистов. Ее описания делались еще в докорпусную эпоху; самыми важными представляются наблюдения, сделанные в статье (Padučeva 1987), недавно напечатанной по-русски с некоторыми сокращениями и одновременно дополнениями (Падучева 2018: 333-352). В ней различные употребления же классифицируются с учетом ее положения в высказывании. Же в позиции, которую Е. В. Падучева называет «свободной», бывает двух типов: же тождества (За столом сидела та же женщуина) и же незамедлительности (Он пришел в первый же вечер). В позиции Ваккернагеля (после первого ударного слова в клаузе), которую Е. В. Падучева называет «начальной», же может относиться к одному из четырех типов: же противительное (Моею будет век Людмила, Руслан же гробу обречен), же обоснования (Он же гений), же следствия (Здорово же ты увлекся, если ничего не сльшал; Что же мне в таком случае делать?; Так поди же попляши) и же присоединительное, иллюстрируемое примером В. З. Санникова Коля добр, доброта же зачастую беззащзитна ${ }^{4}$. Выделенные типы употребления слова же различаются своими просодическими характеристиками.

После появления электронных корпусов, в первую очередь НКРЯ, оказалось возможно использовать их данные. В частности, именно на основе этих данных было выполнено лексикографическое описание частицы же (которая после гласных в неформальной речи может выступать в виде ж) в АС. В соответствующей словарной статье вслед за традиционными описаниями разграничиваются употребления же в качестве частицы и в качестве союза. При этом отмечается, что употребления же в качестве союза не характерны для живой современной речи: первое из них (же 4) характеризуется как необиходное, а второе (же 5) - как книжное. Довольно редкое же 5 толкуется в АС как 'Говорящий во втором предложении поясняет то, о чем говорилось в первом предложении'; оно соответствует значению, которое Е. В. Падучева обозначила как же противительное. Заметим, что же 4 соответствует же противительному по Е. В. Падучевой (примеры на же 4 в АС - Они уехали, мы же остались; Муж изелыми днями работал, жена же ходила по магазинам; Раньше это слово было очень употребительно, в современном же языке встречается редко); оно встречается в русских текстах несколько чаще, чем несколько искусственное для современного языка же 5, но тоже может считаться относительно редким.

Гораздо более характерны для современной речи употребления, рассматриваемые в АС как примеры не союза, а частицы же (именно они составляют подавляющее большинство употреблений же в русских переводах с английского языка, вошедших в параллельный подкорпус НКРЯ). Приведем синопсис этих употреблений по АC:

же 1 'ведь': Я же просил!

же 2 усилительная: Как же это могло случиться?

же 3.1 отождествительная: Адрес тот же?

же 3.2 'с минимальным промежутком': B первый же день пребывания

Помимо это в АС упоминается ряд идиом с частицей же.

Прежде чем рассматривать разные типы употребления частицы же в переводах, полезно обратиться к понятию прагматической обязательности, введенному в статье (Levontina, Shmelev 2005), тем более что, хотя статья в основном была посвящена русской частице ещзе (в одном из типов употреблений), в ней кратко рассматривалась и частица же. В этой статье упоминались некоторые контексты, в которых частица же оказывается прагматически обязательной в том смысле, что ее устранение делает высказывание неидиоматичным или меняет его иллокутивную

\footnotetext{
${ }^{2}$ Ср., напр., публикации некоторых из докладов (Кобозева, Орлова 2008; Добровольский, Левонтина 2012; 2014; 2015; 2017; Добровольский, Зализняк 2018).

${ }^{3}$ См., в частности (Шмелев 2015; Шмелев, Зализняк 2017).

${ }^{4}$ В книге (Санников 2008: 278) используется выражение «же присоединения или обобщения».
} 
функцию. Так, фраза Hу что же mbl! очень естественно понимается как упрек, в то время как фраза Hy что mы!! может пониматься как выражение несогласия, или как поторапливание, или, возможно, как-то иначе, но не как упрек. Вопрос Как так? может пониматься только как выражение недоумения, в отличие от вопроса Как же так?, у которого гораздо больше возможных интерпретаций.

Там же отмечалась некоторая парадоксальность употребления лингвоспецифичных прагматически обязательных частиц в переводных текстах. Если в том или ином языке некоторая частица прагматически обязательна в данном типе контекстов и человек переводит подобный контекст на данный язык с языка, в котором аналогичного показателя нет, то он оказывается перед выбором. Если он переведет фразу буквально, без частицы, то, точно передав смысл, он тем не менее получит неадекватный перевод, содержащий ложную импликатуру. Если же он добавит во фразу частицу, а вместе с ней и смысл, которого, строго говоря, не было в исходном тексте, то, несмотря на добавление нового смысла, перевод будет более адекватным.

Это иллюстрировалось в том числе на примере частицы же, однако в качестве материала был использован всего один текст - Winnie-the-Pooh Алана Милна в переводе на русский язык (точнее, пересказе) Бориса Заходера (Винни Пух и все-все-все). Отмечалось, что частица же часто появляется в заходеровском переводе, когда в оригинале ей, казалось бы, ничего не соответствует. Впрочем, там же отмечалось, что же в переводе Заходера во многих случаях возникает тогда, когда в английском тексте в соответствующей фразе некоторые слова выделены курсивом (можно добавить - иногда посредством капитализации). Иными словами, частица же соответствует эмфатическому выделению в оригинале. По-видимому, именно использование же в качестве показателя эмфатического выделения дает основание говорить о значении «усиления», которое выделяется едва ли не во всех толковых словарях русского языка.

Впрочем, случаи появления частицы же (или любого другого дискурсивного слова) в переводе можно отнести к одному из двух типов: когда частица действительно оказывается прагматически обязательной (так что ее отсутствие привело бы либо к аномалии, либо к ложной импликатуре) и когда ее появление в тексте - сознательный или бессознательный выбор переводчика, хотя можно было бы обойтись и без нее (Zalizniak, Shmelev 2017). Вообще говоря, оба случая заслуживают внимания: семантика дискурсивного слова проясняется не только в тех контекстах, когда оно прагматически обязательно, но и в тех, когда, казалось бы, без него можно обойтись, но тем не менее носитель языка (в рассматриваемых случаях - переводчик) предпочитает его использовать.

Более того, случаи «прагматической обязательности» частицы тоже неоднородны. К ним относятся как случаи, когда действительно нельзя обойтись без данной частицы (иначе возникают нежелательные прагматические сдвиги), так и случаи, когда некоторый дискурсивный показатель необходим, но при этом возможен выбор между разными показателями: напр., при повторной просьбе или уговаривании могут использоваться разные частицы, но почти невозможно или прагматически неадекватно повторение просьбы без какого бы то ни было показателя: если на просьбу выключить телевизор адресат речи никак не реагирует, то в зависимости от ряда прагматически значимых факторов говорящий может повторить просьбу с разной степенью категоричности, сказав нечто вроде Ну выключи телевизор; Да выключи телевизор; Выключи же телевизор; но едва ли уместно будет просто сказать Выключи, пожалуйста, телевизор, не маркировав просьбу как повторную (Левонтина 1999).

Принимая во внимание все указанные разграничения, можно обратиться к случаям использования частицы же в русских переводах с английского языка. Сразу следует сказать, что ввиду несбалансированности англо-русского параллельного подкорпуса НКРЯ статистический анализ на нем не имеет особого смысла. Необходимо содержательное рассмотрение каждого отдельного случая. Ограниченный объем статьи не позволяет останавливаться на деталях - изложены будут лишь результаты анализа в самом общем виде.

Следует сразу сказать, что, по-видимому, сочетания $m$-местоимений с же можно рассматривать не как свободные сочетания слов, а как единые идиоматичные единицы, в которых же представляет собою нечто вроде постфикса, подобного таким постфиксам, как -то и -нибудb, присоединяемым к к-местоимениям. Эти местоименные единицы устойчиво используются для перевода английского same или выражений, содержащих same. К местоимениям тот же, этот же и 
такой же часто присоединяется слово самый, а на базе местоимения тот же образуется фразеологический комплекс один и тот же.

Обратим внимание на различие выражений тот же (самый) и один и тот же (в английском оригинале им часто соответствует одно и то же выражение, включающее слово same). Местоимение тот же предполагает отождествление объекта A1 с некоторым A2, фигурирующим в ситуации $\mathrm{S}$ и предположительно известным адресату речи; при этом $\mathrm{A} 2$ или $\mathrm{S}$ может уже быть в поле внимания адресата речи, напр. упоминаться в предшествующем тексте, или же вводиться в подчиненной клаузе ( $A 1$ то же, что и $A 2 ; A 1$ тот же, что и в $S$ ). Напротив того, выражение один и тот же предполагает, что сравниваются А1 и А2 (а возможно, и А3, A4 и т. д.), коммуникативный статус которых в общем одинаков. Ср. примеры, в которых тот же (самый) и один и тот же очевидным образом не взаимозаменимы:

(1) The answer is the same as for the genetic replicator. - Ответ будет тот же, что и для генетического репликатора. [Ричард Докинз. Расширенный фенотип: длинная рука гена (А. Гопко, 2010)]

(2) Just from me repeating the same words enough times, and pointing to objects, he had learned the Russian words for those objects. - Просто из-за того, что я повторял одни и те же слова достаточно времени и указывал на объекты, он узнал русские обозначения этих объектов. [Почему я учил своего сына говорить по-русски? (Inоsтi.ru, 2018)]

(3) Thirty years ago Richard Collins wrote that pilots, by observing the uniform precision of autoland touchdowns, would improve their performance. Now they are saying the same thing about HUDs... - Tридиать лет назад Ричард Коллинз писал, что пилоть, наблюдая за однообразной точностью автоматических посадок, улучшат свои показатели. Теперь то же самое говорят об индикаторах на лобовом стекле... [Дэвид Минделл. Восстание машин отменяется! Мифы о роботизации. (В. Краснянская, 2017)]

(4) When everyone is claiming the same thing, it's almost impossible to make your product stand оит. - Когда каждый твердит одно и то же, практически невозможно выделить ваш продукт из общей массы. [Народу виднее (ng.ru) (2015)]

Используя данные параллельного англо-русского подкорпуса НКРЯ, попытаемся уточнить толкование значения же 3.1, сформулированное в АС. Приведем это толкование полностью: «А1 же 'A1 совпадает или почти совпадает с тем, о чем шла речь раньше' [часто после слов $\mathrm{mom}$, этот, такой, сей, столько, там, здесь, тут, туда, оттуда, тогда, так, потому, поэтому, затем; подобный, сходный, сам]». Сразу можно сказать, что значение частицы же после $m$-местоимений (тот, такой, столько, там, туда, оттуда, тогда, так, потому, затем) не отвечает данному толкованию. По существу, она представляет собою постфикс, в соединении с которым местоимение выражает тождество, но не обязательно «с тем, о чем шла речь раньше»: очень часто это тождество с тем, о чем идет речь в последующей подчиненной клаузе:

(5) South Ossetia is the same as Kosovo. - Южная Осетия - то же самое, что Косово. [Десять главных мифов о России, ее лидере и ее силе (inosmi.ru) (2008)]

(6) Elephants survived also, but the life of an elephant today is largely the same as it was millions of years ago. - Слоны, конечно, тоже выжили, но их жизнь такая же, как и миллионь лет назад. [Саймон Синек. Лидеры едят последними. Как создать команду мечть (Е. И. Животикова, 2015)]

(7) Indeed the two programs could swap physical computers every other game, each one running alternately in an IBM and an ICL computer, and the result at the end of the tournament will be the same as if one program consistently ran in the IBM and the other consistently ran in the ICL. - Программы вообще могут обмениваться носителями перед каждой новой партией - например, выполняясь по очереди в компьютерах IBM и ICL, — но результат в 
конце соревнования будет таким же, как если бы одна программа постоянно запускалась на компьютере IBM, а другая - на ICL. [Ричард Докинз. Расширенный фенотип: длинная рука гена (А. Гопко, 2010)]

При этом, когда тождество устанавливается с тем, о чем идет речь в последующей подчиненной клаузе, местоимение с же часто может быть заменено соответствующим $m$-местоимением без же. А когда тождество устанавливается с тем, о чем шла речь ранее, замена обычно невозможна, и это можно считать еще одним аргументом в пользу того, что $m$-местоимение с же представляет собою единый комплекс, который разумно считать особой единицей, «отождествительным» местоимением. Ср.:

(8) Greece vehemently opposes its northern neighbor's use of "Macedonia" without a qualifier, because a region in Greece bears the same naтe. - Греция активно возражает против использования её северным соседом в своём названии слова «Македония» без какого-либо дополнительного определения, потому что в Греции есть регион, который называется точно так же. [Свежий импульс на Балканах (Inоsті.ru, 2018)]

(9) A few boys were making their way to the cricket-field; and two or three shopkeepers who were standing at their doors looked as if they should like to be making their way to the same spot... Несколько молодых людей направлялись к крикетному полю, а два-три лавочника, стоя у дверей своих лавок, имели такой вид, словно им хотелось отправиться туда же...

[Чарльз Диккенс. Посмертные записки Пиквикского клуба (А. В. Кривиова, Е. Л. Ланн, 1933)]

Однако, как мы видели, в АС в ряду слов, после которых частица же часто используется в значении отождествления, упоминаются не только $m$-местоимения. Действительно, употребление же в значении отождествления не после $m$-местоимений также встречается, и, хотя частица

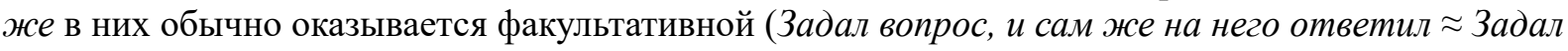
вопрос, и сам на него ответил), она тем не менее нередко появляется в переводных текстах, напр.:

(10) And here he wrote 'a poor physician'. And it was he, without doubt, who scratched a calendar on this stone. - А вот тут он приписал: «несчастный доктор». И он же, конечно, нацарапал и этот календарь, вот здесь, на камне. [Чарльз Диккенс. Повесть о двух городах (М. П. Богословская, С. Я. Бобров, 1950-1960)]

(11) A similar distancing happened with Einstein's wife, Mileva. - Подобное же отдаление произошло и мељжу Эйнштейном и его женой, Милевой. [Дэвид Боданис. Е=тс2. Биография самого знаменитого уравнения в мире (С. Б. Ильин, 2009)]

(12) Here haunted of yore the fabulous Dragon of Wantley; here were fought many of the most desperate battles during the Civil Wars of the Roses; and here also flourished in ancient times those bands of gallant outlaws, whose deeds have been rendered so popular in English song. - Пo преданию, здесь некогда обитал сказочный уонтлейский дракон; здесь происходили ожесточенные битвы во время междоусобных войн Белой и Алой Розы; и здесь же в старину собирались ватаги тех отважных разбойников, подвиги и деяния которых прославлены 8 народных песнях. [Вальтер Скотт. Айвенго (Е. Бекетова, 1890-1902)]

(13) He gazed once again into the void of night, feeling dwarfed by the events he had put into motion. - И чтобы успокоиться, он снова выглянул во тьму ночи, чувствуя себя игрушкой в водовороте событий, которым сам же положил начало. [Дэн Браун. Код Да Винчи (H. Рейн, 2004)]

Именно такое употребление адекватно описывается толкованием, сформулированным в АС.

Впрочем, можно добавить, что стоило бы устранить из списка слов, после которых часто употребляется частица же в значении отождествления, слово тут. В принципе выражение тут же 
может означать ‘приблизительно в этом же месте' и примеры такого рода даже можно обнаружить в англо-русском подкорпусе НКРЯ. Ср.:

(14) A young couple close by flirted a fan by turns, making an unpleasant draught. Francie and one of her lovers stood near. - Одна пара неподалеку от него кокетливо обмахивалась по очереди веером, и Сомсу был неприятен ветер, который они подняли. Тут же рядом остановилась Фрэнси с кем-то из своих поклонников. [Джон Голсуорси. Собственник (Н. Волжина, 1946)]

Но несравненно чаще тут же используется в значении 'в этот момент, немедленно'. Употребление же в этом случае непосредственно связано со значением, которое в АС обозначено как же 3.2; однако, поскольку рассматриваемое значение не складывается из значений тут и же 3.2 и же нельзя устранить без коренного изменения смысла (в отличие от сочетаний, в которых фигурирует же 3.2, напр. сразу же, сейчас же, завтра же) естественно считать тут же идиомой; было бы целесообразно включить это выражение в список идиом с частицей же.

Это побуждает нас еще раз обратиться к упомянутому выше списку идиом из словарной статьи же в АС. Полностью он выглядит следующим образом: «всё же см. ВЕСЬ; одно и то же см. ОДИ́Н; к тому же см. ТО, надо же см. НА́ДО, или же см. ЙЛИ, туда же см. ТУДА́, Как же! cм. КАК». Сразу же возникают вопросы, уже не связанные с использованием частицы же в переводах с английского языка. Так идиома всё же содержит отсылку к словарной статье слова весь (автор - Е. В. Урысон), но в ней идиома всё же вовсе не упоминается. Зато в АС есть отдельная словарная статья всё же (автор - В. Ю. Апресян), и на нее и следовало бы сослаться. Остается непонятным, почему идиома один и тот же приводится в форме среднего рода. А в отношении идиомы как же следовало бы добавить, что, хотя ироническое употребление выражения Как же! вполне конвенционализовалось, так что в подавляющем числе случаев оно означает отрицание ( $\approx$ 'Нет'), но любопытно, что если оно предваряется союзом $a$, то значение подтверждения, выраженное риторическим вопросом, сохраняется: $A$ как же! ( $\approx$ ‘Да, конечно; а как же иначе? ') Собственно, материалы НКРЯ это только подтверждают. Ср., с одной стороны, пример с подразумеваемым иронически-экспрессивным отрицанием:

(15) “... I know something that's better." "I bet you don't. ...”- Я знаю средство получше. - Знаешь тыл, как же! [Марк Твен. Приключения Тома Сойера (Н. Дарузес, 1950)]

И с другой - всего лишь два из многочисленных примеров, в которых очевидно подтверждение, выраженное риторическим вопросом:

(16) Is your husband going over there to-night? Oh, yes. - A ваш муж поедет туда нынче ночью? - Ну а как же! [Марк Твен. Приключения Гекльберри Финна (Н. Дарузес, 1950)]

(17) Will we see you at the camp? - Yes, man. - Мы увидимся в лагере? мингуэй. По ком звонит колокол (Н. Волюсина, Е. Калашникова, 1968)

Таким образом, упоминание идиом с частицей же в АС тоже нуждается в некотором уточнении. Перейдем к употреблению частицы же в вопросительных предложениях. Соответствующее значение (же 2) истолковано в АС следующим образом: «Какой же $A$ ? 'Задавая вопрос, говорящий подчеркивает, что он не может знать ответа на него' [после вопросительных слов кто, что, какой, чей, который, сколько, где, куда, откуда, когда, как, почему, зачем]». Не требуется обращения к англо-русскому подкорпусу НКРЯ, чтобы увидеть неточность в данном толковании. В самом деле, если учитель говорит ученику: «Вы говорите, что группа “Освобождение труда" была создана в 1883. Хорошо. А кто же в нее входил?», - то совершенно не предполагается, что учитель не знает ответа на заданный вопрос: напротив того, скорее всего учитель знает ответ и хочет проверить, знает ли его ученик. Можно добавить, что в некоторых «риторических» употреблениях вопросительное предложение с же выражает возражение (напр., Что же в этом плохого?).

\footnotetext{
${ }^{5}$ Ср. [Шмелев 2009: 186].
} 
По-видимому, АС толковал эту частицу лишь в контексте прототипического (прямого, информационного) вопроса, не учитывая иллокутивного разнообразия вопросительных предложений с частицей же после вопросительного местоимения.

Перечисление в квадратных скобках вопросительных слов, после которых же может употребляться в рассматриваемом значении, наводит на мысль, что же может употребляться только в частных, но не в общих вопросах. Ср. в связи с этим беглое замечание (Падучева 2018: 344; сноска), согласно которому же «невозможно в общем вопросе (*Так пошел же он в магазин?)». Впрочем, в этой же сноске, со ссылкой на работу Д. Пайара, Е. В. Падучева отмечает, что же все же возможно в вопросах с частицей неужели (Неужели же ты не узнал свою работу?), но не в вопросах с частицей разве (*Разве же ты не узнал свою работу?). Заметим, что запрет на использование же в вопросах с частицей разве сформулирован излишне категорично: риторические вопросы, начинающиеся с разве ж, нередко используются в просторечии. Многим памятна сцена из «Архипелага ГУЛАГ»:

(18) Так на истолчённой соломке пола стало нас восемь сапог к двери и четыре шинели. Они спали, я пылал. Чем самоуверенней я был капитаном полдня назад, тем больней было защемиться на дне этой каморки. Раз-другой ребята просыпались от затеклости бока, $и$ мы разом переворачивались.

К утру они отоспались, зевнули, крякнули, подобрали ноги, рассунулись в разные угль началось знакомство.

- A mы за что?

Но смутный ветерок настороженности уже опахнул меня под отравленной кровлею СМЕРШа, и я простосердечно удивился:

- Понятия не имею. Рази ж говорят, гады?

Просторечная форма частицы разве (рази) вполне согласуется с общей просторечной окраской высказывания.

В основном подкорпусе НКРЯ (новая версия) по данным на 1 марта 2021 нашлось 320 вхождений сочетания разве же, и, кстати, не всегда в них ощутим налет просторечия. Но особенно показательно, что три таких примера обнаруживаются и в англо-русском подкорпусе НКРЯ, причем во всех трех случаях переводчик стремится имитировать просторечную окраску высказывания:

(19) Who's made appointments with him in the hold? Ain't that queer, now? - Kто это ему maм 6 трюме свидания назначает? Ну разве ж это не странно? [Герман Мелвилл. Моби Дик (И. М. Бернштейн, 1961)]

(20) But I am not a brave тап... - Так разве ж я храбрый человек... [Герман Мелвилл. Моби Дик (И. М. Бернштейн, 1961)]

(21) DOOLITTLE (remonstrating) Now, now, look here, Governor. Is this reasonable? Is it fairity to take advantage of a man like this? - ДУЛИТТЛ (протестующе). Но-но, хозяин, так не годится. Разве ж это по-честному? Разве так поступают с человеком? [Бернард Шоу. Пигмалион (Н. Рахманова, П. Мелкова, 1993)]

В целом же можно согласиться с формулировкой, согласно которой же маркирует «вопрос, порожденный предшествующим контекстом» (Падучева 2018: 344) 6 . Конечно, в таком виде ее затруднительно использовать в словарном толковании рассматриваемого значения же. Общий смысл вопросов с частицей же можно было бы сформулировать, напр., так: 'Ты понимаешь, что сложившаяся ситуация естественно вызывает данный вопрос' (вопрос может быть и риторическим). Примеров, подтверждающих такое толкование, в англо-русском подкорпусе НКРЯ довольно много.

\footnotetext{
${ }^{6}$ В статье (Пекелис 2020), посвященной микроэволюции частицы же в вопросительных предложениях в языке XVIII-XIX вв., выделяется четыре разновидности вопроса с же в современном языке: недоумение, несогласие, непонимание, нетерпение.
} 
Выходя за рамки НКРЯ, можно упомянуть историю, рассказанную в книге Лео Ростена The Joys of Yiddish:

(22) Mr. Sokoloff has had dinner for twenty years in the same restaurant on the Second Avenue. This evening, as always, he orders bouillon. The waiter brings it, and wants to go back, but Mr. Sokoloff addresses him: "Waiter!"- "Yes, please?" - "Be so kind to taste this soup." - "But Mr. Sokoloff, you have come here for twenty years and you have never complained." -

"Please", repeats Mr. Sokoloff obstinately, "taste this soup." - "But what is the matter, Mr. Sokoloff?" - "Please taste it." - "All right", the waiter says. "But... a moment. Where is the spoon?" - "Aha!", says Mr. Sokoloff.

В (Шмелев 2015: 590) отмечалось, что почти все, кто прочел эту историю и хочет рассказать ее на русском языке, передают последние фразы официанта следующим образом: Но... минуточку. Где же ложка? Частица же почти неизбежно появляется в переводе и прересказе.

Иногда при помощи такого вопроса говорящий высказывает упрек адресату речи, напоминая ему о чем-то, что может служить основанием для упрека (Что же ты не выполнил обещания?). Но для англо-русского подкорпуса НКРЯ такие употребления почему-то совершенно не характерны. Возможно, такого рода упреки не характерны для англоязычного дискурса как такового.

Наконец, обратимся к самому частотному значению частицы же, которое обозначено в АС как же 1. Оно истолковано в АС следующим образом: «A1 же 'Говорящий подчеркивает, что А1 должно быть известно адресату речи’». В комментарии к толкованию говорится: «Часто используется при выражении упрека, повторного требования, напоминания и выражает различные эмоции». Такие употребления характерны для диалогического режима, и в англо-русском подкорпусе НКРЯ они в основном встречаются в переводах диалогов (поэтому они не столь многочисленны, как можно было бы ожидать). Ср.:

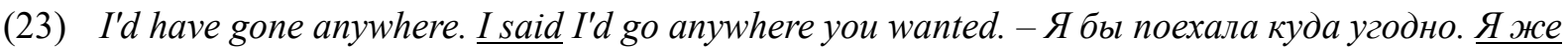
говорила, что поеду, куда только ты захочешь. [Эрнест Хемингуэй. Снега Килиманджаро (Н. Волжина, 1956)]

(24) I said I didn't want... - Я сказал же, что не хочу... [Уильям Голдинг. Повелитель мух (E. Суриu, 1985)]

(25) And all the nicest things that Puzzle brought back were eaten by Shift; for as Shift said, "You see, Puzzle, I can't eat grass and thistles like you, so it's only fair I should make it up in other ways." - Все вкусное, что ослик приносил из города, съедал Хитр, и при этом говорил: «Ты же понимаешь, я не могу есть траву и чертополох как ты, и по справедливости я должен это чем-то возмещать». [Клайв Стейплз Льюис. Хроники Нарнии. Последняя битва (Г. А. Островская, 1991)]

(26) You know you're no good at thinking, Puzzle, so why don't you let me do your thinking for you? тыл же знаешь, что не слишком хорошо умеешь думать, так уж позволь мне думать за тебя. [Клайв Стейплз Льюис. Хроники Нарнии. Последняя битва (Г. А. Островская, 1991)]

Толкование АС представляется вполне адекватным. Возможно, впрочем, что глагол подчеркивать в толковании не вполне точен: говорящий скорее исходит из того, что А1 известно адресату речи, и использует A1 как обоснование чего-то, что, по его мнению, адресат речи не учитывает. При этом, как отмечалось в (Падучева 2018: 341), аргумент, выраженный при помощи предложения с же, «обычно слабый, как бы не решающий». Часто же выражает раздражение по поводу пренебрежения очевидностью.

Заметим, что в контекстах такого рода мы сталкиваемся с упомянутой выше разновидностью прагматической обязательности. В большинстве случаев же 1 может быть заменено на частицу ведb (позиция которой в предложении более свободна). Однако отсутствие какого бы то ни было показателя сделало бы высказывание прагматически неадекватным: оно не могло бы восприниматься как аргумент, пусть даже слабый. 
Итак, материал англо-русского подкорпуса НКРЯ позволяет уточнить описание частицы же, данное в АС. В частности, было высказано предположение, что в сочетаниях с $m$-местоимениями же следовало бы описывать как постфикс (а соответствующие сочетания - как производные местоимения). Разумеется, такие уточнения можно было бы сделать и без опоры на параллельный корпус, используя лишь оригинальные русские тексты, а также лингвистический эксперимент. Однако параллельный корпус позволяет представить некоторые свойства частицы максимально наглядно. Выявляя причины, которые побудили переводчиков использовать частицу же в своих переводах мы получаем шанс увидеть какие-то ее свойства, которые в противном случае могли бы ускользнуть от внимания. Остается вопрос: если бы подключить к анализу материалы переводов с других языков, насколько это повлияло бы на общие выводы? Этот вопрос нуждается в дальнейшем исследовании.

\section{References}

[1] Dobrovolskii D. O., Levontina I. B. (2012) Synonymous focus particles in German and Russian, Computational Linguistics and Intellectual Technologies: Proceedings of the International Conference Dialogue'2012, vol. 1, Moscow, pp. 138-149.

[2] Dobrovolskii D. O., Levontina I. B. (2014) Discourse words in general questions: Russian-German nearequivalents, Computational Linguistics and Intellectual Technologies: Proceedings of the International Conference Dialogue'2014, Moscow, pp. 138-149.

[3] Dobrovolskii D. O., Levontina I. B. (2015) Modal Particles and the Actualization of Forgotten Details (Based on the Materials of Parallel Corpora), Computational Linguistics and Intellectual Technologies: Proceedings of the International Conference Dialogue'2015, vol. 1, Moscow, pp. 104-117.

[4] Dobrovolskii D. O., Levontina I. B. (2017) Discourse Particles and Their Translation: Nu in Vladimir Sorokin's Novel The Queue (Ochered'), Computational Linguistics and Intellectual Technologies: Proceedings of the International Conference Dialogue'2017, vol. 2, Moscow, pp. 106-117.

[5] Kobozeva I. M., Orlova S. V. (2008) Unicellular organisms of communication under a microscope: German particle $j a$ versus its Russian translation equivalents ved' and že, Computational Linguistics and Intellectual Technologies: Proceedings of the International Conference Dialogue'2008, Moscow, pp. 199-205.

[6] Levontina I. B. (2017) Zhe, V. Apresjan, I. Galaktionova, B. Iomdin (eds.) Active Dictionary of Russian, [Aktivnyi slovar'russkogo iazyka], vol. 3, Nestor-Istoriia, Moscow; Saint Petersburg.

[7] Levontina I. B. (1999), Strategies of coaxing: particles in repeated requests [Strategii ugovarivaniia: chastitsy v povtornykh pros'bakh], Language. Culture. Humanities. Scientific heritage of G. O. Vinokur today [Iazyk. Kul'tura. Gumanitarnoe znanie. Nauchnoe nasledie G. O. Vinokura i sovremennost'], Nauchnyi Mir Publ., Moscow, pp. 188-201.

[8] Levontina I., Shmelev A. (2005), The particles one cannot do without // East-West Encounter: Second International Conference on Meaning $\leftrightarrow$ Text Theory, Slavic Culture Languages Publishing House, Moscow, pp. 258-267.

[9] Padučeva E. V. (1988) The particle zhe: semantics, syntax, and prosody [La particule ŽE: semantique, syntaxe et prosodie], Narrative particles in modern Russian [Les particules énonciatives en Russe contemporain], Institut d'études slaves, Paris, vol. 3, pp. 11-44.

[10] Paducheva E. V. (2018) Egocentric linguistic items [Egotsentricheskie edinitsy iazyka], Izdatel'skii Dom IaSK Publ., Moscow, 2018

[11] Pekelis O. E. (2020) A Case of Pragmaticalization in Russian: Micro-diachronic Analysis of the Particle že in Questions. Slověne, vol. 9, № 1, pp. 340-361.

[12] Shmelev A. D. (2009) "Void" and "unexpressed" negation ["Neznachashchee" i "nevyrazhennoe" otritsanie], Logical Analysis of Language: Assertion and Negation [Logicheskii analiz iazyka: assertsiia i negatsiia], Indrik Publ., Moscow, pp. 173-202.

[13] Shmelev A. D. (2015) Russian Language-specific Lexical Units in Parallel Corpora: Prospects of Investigation and "Pitfalls", Computational Linguistics and Intellectual Technologies: Proceedings of the International Conference Dialogue'2015, vol. 1, Moscow, pp. 584-594.

[14] Shmelev A. D., Zalizniak Anna A. (2017), Reverse translation as a tool for analysis of discourse words, Computational Linguistics and Intellectual Technologies: Proceedings of the International Conference Dialogue' 2017, Moscow, pp. 370-380.

[15]Zalizniak Anna, Shmelev A. (2017) Russian discourse words in the light of parallel corpora [Russkie diskursivnye slova po dannym parallel'nykh korpusov], available at: https://www.aatseel.org/100111/pdf/abstracts/1419/Zalizniak.pdf 


\section{Литература}

[1] Levontina I., Shmelev A. The particles one cannot do without // East—West Encounter: Second International Conference on Meaning $\leftrightarrow$ Text Theory. — Moscow: Slavic Culture Languages Publishing House, 2005. P. 258-267.

[2] Padučeva E. V. La particule ŽE: semantique, syntaxe et prosodie // Les particules énonciatives en Russe contemporain. — Paris : Institut d'études slaves, vol. 3, 1988. — P. 11-44.

[3] Zalizniak Anna, Shmelev A. Русские дискурсивные слова по данным параллельных корпусов // AATSEEL: Program of the 2017 Annual Meeting, https://www.aatseel.org/100111/pdf/abstracts/1419/Zalizniak.pdf

[4] Добровольский Д. О., Левонтина И. Б. О синонимии фокусирующих частиц (на материале немецкого и русского языков) // Компьютерная лингвистика и интеллектуальные технологии. По материалам международной конференции Диалог'2012. Т. 1. — Москва, 2012. - С. 138-149.

[5] Добровольский Д. О., Левонтина И. Б. Дискурсивные слова в общевопросительных предложениях: русско-немецкие соответствия // Компьютерная лингвистика и интеллектуальные технологии. По материалам международной конференции Диалог'2014. - Москва, 2014. - С. 138-149.

[6] Добровольский Д. О., Левонтина И. Б. Модальные частицы и идея актуализации забытого (на материале параллельных корпусов) // Компьютерная лингвистика и интеллектуальные технологии. По материалам международной конференции Диалог'2015. Т. 1. — Москва, 2015. — С. 104-117.

[7] Добровольский Д. О., Левонтина И. Б. Дискурсивные частицы и способы их перевода: 'ну' в романе Владимира Сорокина «Очередь» // Компьютерная лингвистика и интеллектуальные технологии. По материалам международной конференции Диалог'2017. Т. 2. - Москва, 2017. - С. 106-117.

[8] Кобозева И. М., Орлова С. В. Одноклеточные организмы общения под микроскопом: немецкая частица $а$ в сопоставлении с ее переводными эквивалентами ведь и же // Компьютерная лингвистика и интеллектуальные технологии. По материалам международной конференции Диалог'2008. Москва, 2008. - С. 199-205.

[9] Левонтина И. Б. Ж И. В. Галактионова, Б. Л. Иомдин. Под общим руководством акад. РАН Ю. Д. Апресяна. - Москва; СПб.: Нестор-История, 2017. - С. 374-375.

[10] Левонтина И. Б. Стратегии уговаривания: частицы в повторных просьбах // Язык. Культура, Гуманитарное знание. Научное наследие Г. О. Винокура и современность. — Москва: Научный мир, 1999. — C. 188-201).

[11] Падучева Е. В. Эгоцентрические единицы языка, - Москва: Издательский дом ЯСК, 2018.

[12] Пекелис О. Е. Об одном случае прагматикализации в русском языке: микродиахроническое исследование частицы же в составе вопроса // Slověne, 2020. — Vol. 9, № 1. — С. 340-361.

[13] Шмелев А. Д. «Незначащее» и «невыраженное» отрицание (когнитивные и коммуникативные источники энантиосемии) // Логический анализ языка. Ассерция и негация. Москва: Индрик, 2009. C. $173-202$.

[14] Шмелев А. Д. Русские лингвоспецифичные лексические единицы в параллельных корпусах: возможности исследования и «подводные камни» // Компьютерная лингвистика и интеллектуальные технологии. По материалам международной конференции Диалог'2015. Т. 1. — Москва, 2015. — С. 584594.

[15] Шмелев А. Д., Зализняк Анна А. Реверсивный перевод как инструмент лингвистического анализа дискурсивных слов // Компьютерная лингвистика и интеллектуальные технологии. По материалам международной конференции Диалог'2017. — Москва, 2017. - С. 370-380. 